\title{
A pilot study of the efficacy of miglitol and sitagliptin for type 2diabetes with a continuous glucose monitoring system and incretin-related markers
}

Miyako Kishimoto* and Mitsuhiko Noda

\begin{abstract}
Background: Glucose fluctuations including robust postprandial hyperglycemia are a risk for promoting atherosclerosis and diabetic complications. The $\alpha$-glucosidase inhibitors and the dipeptidyl peptidase-4 (DPP-4) inhibitors have been found to effectively decrease postprandial hyperglycemia independently. Therefore, glycemic control with the combination of these drugs is warranted.
\end{abstract}

Methods: Continuous glucose monitoring (CGM) was performed for 3 patients with type 2 diabetes and 1 control subject from the beginning to the end of the study. Medications were not administered to any of the subjects on the first day of the study. From the second day to the end of study (days 2-5), the subjects received miglitol (150 mg per day) and on days 4 and 5, sitagliptin (50 mg per day) was added to the treatment regimen. On the first, third, and fifth days of the study, blood was drawn at 0, 30, 60, 120, 180, and 240 min after breakfast for measurements of serum insulin, 1,5-anhydroglucitol (1,5-AG), plasma glucagon, glucagon-like peptide-1 (GLP-1), and glucose-dependent insulinotropic peptide (GIP).

Results: Measurements of CGM and 1,5-AG levels showed that miglitol attenuated the escalation and fluctuation of glucose levels, and this was even more pronounced with the combination of miglitol and sitagliptin. The patterns of insulin secretion and glucagon secretion with miglitol alone or with a combination of miglitol and sitagliptin were various in the study subjects. Miglitol alone enhanced the release of GLP-1 in 1 patient with type 2 diabetes and the control subject, whereas the combination of miglitol and sitagliptin increased GLP-1 levels to varying degrees in all the subjects. Except for 1 subject, none of the subjects showed any change in GIP levels after the addition of sitagliptin, compared to the administration of miglitol alone.

Conclusions: In conclusion, CGM measurements revealed that a combination of the $\alpha$-Gl miglitol and the DPP-4 inhibitor sitagliptin effectively reduced postprandial glucose fluctuation and stabilized blood glucose levels. Completely different response patterns of insulin, glucagon, GLP-1, and GIP were observed among the study subjects with either medication alone or in combination, suggesting that individual hormone-dependent glycemic responses to the $\alpha-G l$ and DPP-4 inhibitors are complicated and multifactorial.

Keywords: miglitol, sitagliptin, glucagon-like peptide-1 (GLP-1), glucose-dependent insulinotropic peptide (GIP), continuous glucose monitoring (CGM)

\footnotetext{
* Correspondence: mkishimo@hosp.ncgm.go.jp

Department of Diabetes and Metabolic Medicine, Center Hospital, and Diabetes and Metabolism Information Center, Diabetes Research Center, National Center for Global Health and Medicine, 1-21-1 Toyama, Shinjuku-ku, Tokyo, 162-8655, Japan
} 


\section{Introduction}

Patients with type 2 diabetes mellitus are at an increased risk for cardiovascular disease [1,2]. Recent studies have indicated that glycemic variability plays a role in the pathogenesis of atherosclerosis, because acute fluctuations of glucose levels lead to oxidative stress [3-5] and have more deleterious effects on the development of cardiovascular complications in patients with diabetes than sustained hyperglycemia [3-7]. Therefore, improved clinical outcomes in patients with diabetes may be related to the effort to reduce the fluctuations of glucose levels [8].

$\alpha$-Glucosidase inhibitors ( $\alpha$-GIs), a promising class of glycemic control agents delay the absorbance of carbohydrates and decrease both postprandial hyperglycemia and hyperinsulinemia. These agents inhibit the activity of $\alpha$-glucosidase, which is a membrane-bound enzyme located in the epithelium of the small intestine and is involved in the digestion of carbohydrates. By competitively inhibiting the breakdown of carbohydrates, $\alpha$-GIs delay the absorption of digested carbohydrates from the small intestine and thus lower both postprandial glucose and insulin levels [9]. Results of the STOP-NIDDM randomized trial showed that the $\alpha$-GI acarbose could be used, either as an alternative or in addition to a change in lifestyle, to delay the development of type 2 diabetes in patients with impaired glucose tolerance [10].

Another promising class of therapeutic targets for decreasing glucose fluctuations is the incretin-related agents. There has been a recent increased appreciation for the role of incretins in controlling the postprandial metabolic milieu [11]. The incretins, glucagon-like peptide-1 (GLP-1) and glucose-dependent insulinotropic polypeptide (GIP) are released from enteroendocrine cells and enhance insulin secretion [12,13]. Incretins are rapidly inactivated by the enzyme dipeptidyl peptidase- 4 (DPP-4), resulting in a very short half-life. DPP-4 inhibitors, such as sitagliptin, increase active GLP-1 and GIP levels by inhibiting DPP-4 enzymatic activity and improve hyperglycemia in a glucose-dependent fashion by increasing serum insulin and decreasing serum glucagon levels in diabetic patients [14]. In addition, the $\alpha$ GIs reportedly enhance GLP-1 responses and reduce total GIP responses [15-18]. The combination of an $\alpha$ GI and a DPP-4 inhibitor has been reported to increase active GLP-1 levels and additively improve glucose tolerance in mice, compared to DPP-4 inhibitor alone [19]. Considering the different but complementary mechanisms of action by which $\alpha$-GIs and DPP-4 inhibitors lower glucose levels and increase GLP-1 action, a combination therapy with these agents may provide a valuable means of treating diabetes [20].

The aim of the present study is to evaluate the efficacy of miglitol alone and in combination with sitagliptin on changes in blood glucose levels, precisely evaluated by a continuous glucose-monitoring system (CGMS) [21-23], and determine the effect of these agents on changes in insulin, 1,5-anhydroglucitol (1,5 AG), glucagon, GLP-1, and GIP levels in subjects with type 2 diabetes.

\section{Methods}

\section{Subjects}

The baseline characteristics of the 3 Japanese patients with type 2 diabetes who were treated with diet therapy alone or with oral hypoglycemic agents other than $\alpha$-GIs or DPP-4 inhibitors, and 1 Japanese female control subject are summarized in Table 1 . The value for haemoglobin A1c (HbA1c) (\%) was converted to National Glycohemoglobin Standardization Program (NGSP) levels by using the formula: HbA1c (\%)(NGSP) = HbA1c [Japan Diabetic Society (JDS)] $(\%)+0.4 \%$, considering the relational expression of HbA1c (JDS) (\%) measured by the previous Japanese standard substance and measurement methods [24]. All anti-diabetic drugs were washed out for 5 days before each experimental day. The study protocol was approved by the Ethics Committee of the National Center for Global Health and Medicine (NCGM), and written informed consent was obtained from each study subject. The study was conducted in accordance with the ethical principles stated in the Declaration of Helsinki.

\section{Procedure}

\section{Cgms}

The patients were admitted to a diabetic ward at the NCGM and equipped with a CGMS device (CGMSGOLD; Medtronic MiniMed, Northridge, CA, USA). The subjects were monitored for 3 days before the study and until the end of the 5-day study period. The CGMS soft sensor was changed at the proper times according to the manufacturer's instructions. Glucose levels measured with a self-monitoring blood glucose (SMBG) device (Nipro Stat Strip XP; Nipro, Japan) were checked at least 4 times per day for calibration of the CGMS. The recorded data were analyzed with CGMS Solutions software.

\section{Breakfast}

The calories of each breakfast through the study period were determined, considering age and body mass index

\section{Table 1 Subject characteristics}

\begin{tabular}{lcccc}
\hline & Case 1 & Case 2 & Case 3 & Control \\
\hline Age $(\mathrm{yr})$ & 67 & 69 & 76 & 48 \\
Gender & Female & Male & Male & Female \\
BMl $\left(\mathrm{kg} / \mathrm{m}^{2}\right)$ & 26.9 & 26.5 & 24.1 & 22.2 \\
Diabetes duration (yr) & 5 & 11 & 1 & none \\
Treatment & $\mathrm{SU}$ & $\mathrm{SU}+$ Met & Diet only & none \\
Hb A1c (\%) & 7.1 & 7.3 & 7.0 & 5.3 \\
\hline
\end{tabular}

Abbreviations: BMI, body mass index; SU, sulfonyl urea; Met, metformin. 
(BMI) of each patient and the control subject. For example, the mean calories for patients in case $1,2,3$, and the control subject were $310,413,400$, and 470 kcal, respectively.

\section{Sample collection and analysis}

On the first day of the study, after an overnight fast for $14 \mathrm{~h}$, an intravenous line was inserted into 1 forearm vein and flushed with sterile $0.9 \% \mathrm{NaCl}$ solution for repeated blood sampling. Blood was drawn at $0,30,60$, 120,180 , and $240 \mathrm{~min}$ after breakfast (the meal was ingested within 10-15 min) for measurements of serum insulin, 1,5-AG, plasma glucagon, GLP-1, and GIP. Blood samples were immediately cooled and centrifuged at $4^{\circ} \mathrm{C}$, and plasma was stored at $-20^{\circ} \mathrm{C}$ until analysis. Blood samples for determination of active GLP-1 were collected into chilled BD P700 tubes containing spraydried K2EDTA anticoagulant and proprietary DPP-4 protease inhibitor (Becton Dickinson, Franklin Lakes, NJ, USA), and the GLP-1 concentrations were measured using an enzyme-linked immunosorbent assay (ELISA) kit (Millipore Corporation, Billerica, MA, USA). Plasma concentrations of amidated GLP-1 (7-36) and (7-37) were measured using an antibody that is highly specific for the N-terminus of GLP-1 and does not react with GLP-1 (9-36), GLP-2, or glucagon. The detection limit of the ELISA was $2 \mathrm{pmol} / \mathrm{l}$, with an intra-assay coefficient of variation $(\mathrm{CV})$ of $2.6 \%-6.0 \%$ and interassay $\mathrm{CV}$ of $7.1 \%-9.8 \%$. Total GIP was measured using a human GIP ELISA kit (Millipore Corporation). This kit has $100 \%$ cross reactivity to human GIP (1-42) and GIP (342 ), with a detection limit of $1.8 \mathrm{pmol} / \mathrm{l}$, an intraassay CV of $4.8 \%-6.3 \%$, and an interassay CV of $2.2 \%-5.0 \%$. Serum insulin was measured using a chemiluminescent enzyme immunoassay (CLEIA). Blood samples for glucagon measurements were collected in tubes containing EDTA-2Na plus aprotinin and analyzed with a doubleantibody radioimmunoassay. Serum 1,5 AG was measured using an enzymatic method (Nippon Kayaku, Tokyo, Japan). All sample measurements were performed at SRL, Inc. (Tokyo, Japan). Areas under the curve (AUC) values for these hormones after meal ingestion were calculated using the trapezoidal rule.

\section{Medications}

From the second day to the end of the study period, the subjects were prescribed miglitol (50 mg), 3 tablets per day just before every meal. From day 4 through day 5 , the subjects were also prescribed sitagliptin (50 mg), 1 tablet per day before breakfast. Blood sampling was also performed on the third day and the fifth day of the study. The sampling methods and timing were identical for each blood sampling period.

\section{Results}

During the 5-day study period, the subjects experienced no gastrointestinal symptoms with the study medications, and CGM was completed without any problems. Figure 1 shows that the escalation and fluctuation of glucose levels measured by CGM after administration of miglitol alone were attenuated. This attenuation of blood glucose levels was even more pronounced with the combination of miglitol and sitagliptin. The accuracy of these measurements was reflected in the mean and standard deviation (SD) values of CGM measurements, as well as changes in 1,5-AG levels (Table 2).

The time-course levels of glucose (CGM), insulin, insulin to glucose ratio, glucagon, active GLP-1, total GIP, and AUC values for these hormones up to $4 \mathrm{~h}$ after meal ingestion are summarized in Figures 2, 3, 4 and 5 and Table 3. Compared to no medication, miglitol administration attenuated the postprandial increments in plasma insulin levels in all the subjects, including the control subjects. In all subjects except case 3, similar patterns of insulin secretion were seen in insulin to glucose ratios. When sitagliptin was coadministered with miglitol, further attenuation of postprandial increment in insulin was observed in case 3 and the control subject; no remarkable changes in insulin levels were observed in the other subjects. These results were also confirmed by the changes in insulin to glucose ratio. Administration of miglitol had no observable effect on blood glucagon levels after meal ingestion in any subject. Similarly, when sitagliptin was added to miglitol, no remarkable changes in glucagon levels were observed in any of the subjects. Compared to no medication, miglitol administration resulted in slightly higher GLP-1 levels in the patient in case 3 and the control subject, but not in the patients in cases 1 and 2. After sitagliptin was coadministered with miglitol, remarkable incremental increases in GLP-1 levels were observed in all the study subjects. Compared to no medication, miglitol administration resulted in decreased GIP levels in patients in cases 1 and 2 and the control subject, but not in the patient in case 3 . When sitagliptin was added to miglitol, the patient in case 3 and the control subject showed further decreases in GIP levels, which was not observed in the other 2 subjects with diabetes. Compared to no medication, all the subjects showed suppressed GIP levels when miglitol and sitagliptin were coadministered.

\section{Discussion}

The results of the present study showed that an administration of miglitol alone had beneficial effects on postprandial hyperglycemia, and these effects were even more pronounced when sitagliptin was coadministered 


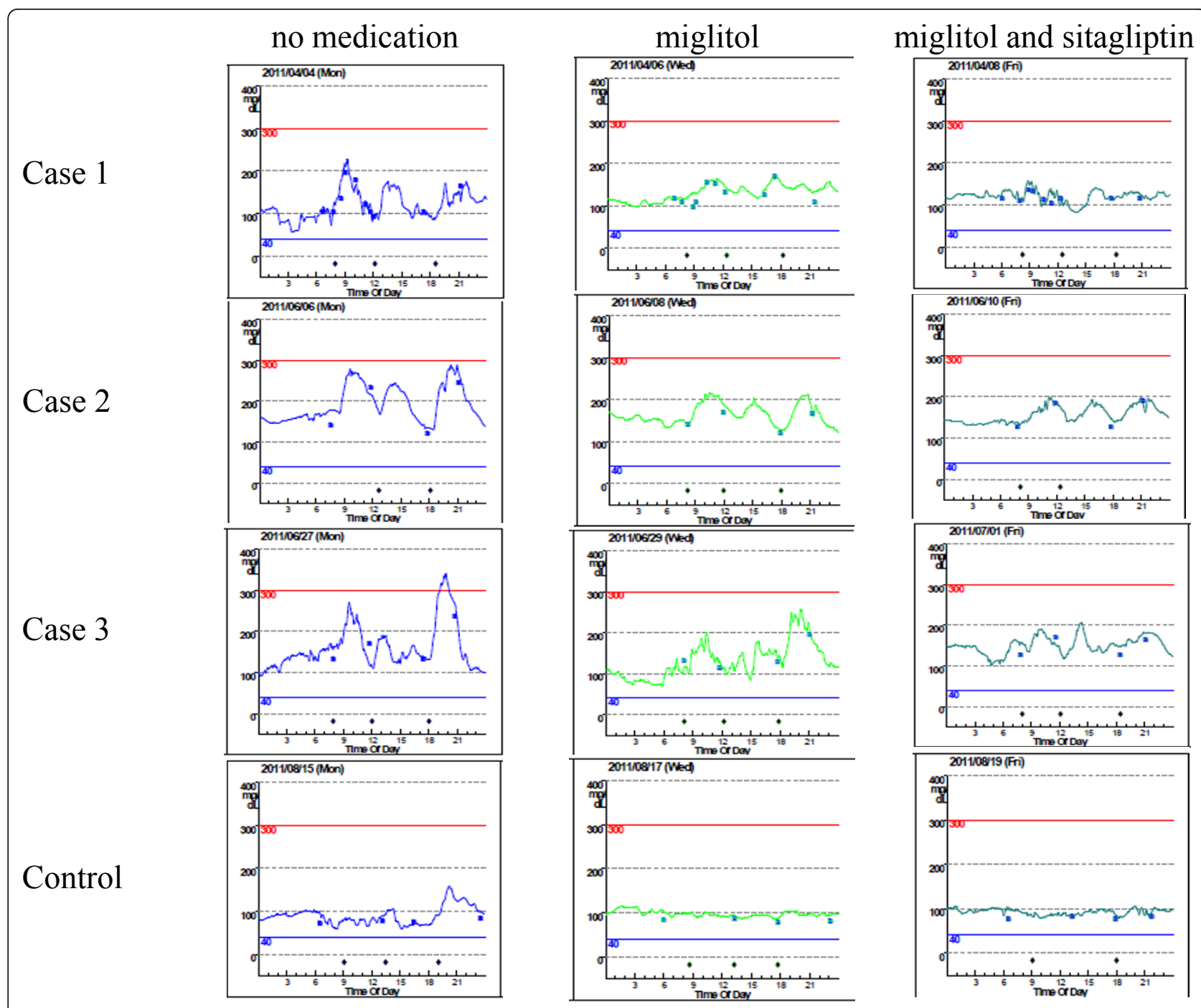

Figure 1 The results of CGM for patients in cases 1 to 3, and the control subject with the conditions of no medication, miglitol alone, and coadministration of miglitol and sitagliptin.

with miglitol. This beneficial effect on hyperglycemia was demonstrated precisely by the mean \pm SD values of the glucose levels monitored with CGMS together with the 1,5-AG levels that reflect glycemic excursions, often

Table 224 hours glucose levels measured by CGM and 1,5-AG levels

\begin{tabular}{lccc}
\hline & Case 1 & Case 2 & Case 3 \\
\hline $\begin{array}{l}\text { Glucose }(\mathrm{mg} / \mathrm{dl}) \text { (Average } \pm \mathrm{SD}) \\
\text { no medication }\end{array}$ & $120 \pm 34$ & $193 \pm 44$ & $161 \pm 55$ \\
$\quad$ miglitol & $131 \pm 19$ & $164 \pm 24$ & $131 \pm 43$ \\
$\quad$ miglitol + sitagliptin & $120 \pm 14$ & $156 \pm 20$ & $151 \pm 21$ \\
$\begin{array}{l}\text { 1,5-AG ( } \mu \mathrm{g} / \mathrm{ml}) \\
\text { no medication }\end{array}$ & 8.5 & 5.9 & 17.6 \\
miglitol & 8.2 & 6.8 & 17.7 \\
miglitol + sitagliptin & 8.8 & 7.9 & 17.9 \\
\hline
\end{tabular}

in the postprandial state, more robustly than $\mathrm{HbA} 1 \mathrm{c}$ or fructosamine measurements $[25,26]$.

In a separate study, Lee et al. reported that miglitol induced enhanced and prolonged GLP-1 release and suppressed plasma GIP secretion after ingestion of an ordinary meal in the case of obese patients with diabetes and glycemic control [17]. These results were supported by the results of a study by Narita et al. who showed consistent enhancing effects of miglitol on GLP-1 responses to a mixed meal in patients with type 2 diabetes $[15,18]$. These investigators also showed that in response to administration of miglitol, plasma glucose, insulin, and GIP levels significantly decreased during the early postprandial phase, and both active and total GLP1 levels were significantly higher during the late postprandial phase. To confirm these results, we also measured insulin, glucagon, GLP-1, and GIP levels after 


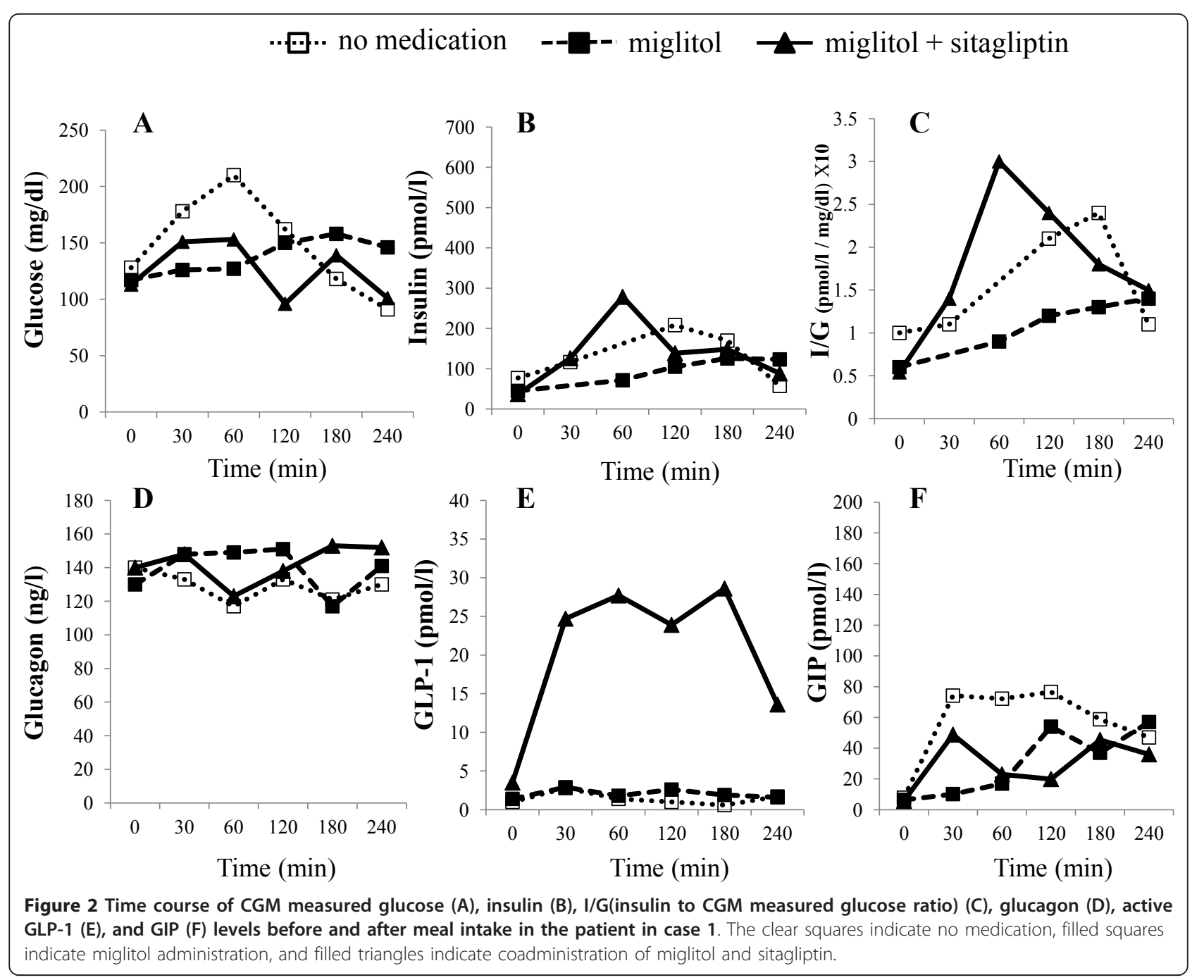

administration of the medications. With miglitol administration, all the subjects exhibited an attenuated postprandial increment in insulin, which may be explained by an induced decrease in blood glucose levels. When we added sitagliptin to miglitol, we theoretically expected a postprandial increment in insulin levels owing to the effect of this drug on GLP-1; however, this phenomenon was observed only in the patient in case 1 , but not in the other subjects. These latter findings can also be partly explained by an induced decrease in blood glucose levels. In support of this hypothesis, Aoki et al. reported that sitagliptin decreased the AUC of blood glucose levels without increasing insulin levels in subjects without diabetes [27]. They also described that this effect may be explained by a decrease in plasma glucagon levels $[14,28]$. The glucose-lowering effect of GLP-1 is based not only on its potent insulinotropic action, but also on its ability to restrain glucagon secretion. To date, it is unknown whether GLP-1 directly suppresses glucagon release by binding to GLP-1 receptors expressed on the alpha cell, or indirectly by modulating the release of secretory products, such as insulin [29], somatostatin [30-32], or others, from the beta or delta cells. In our subjects, the decrease in glucagon levels was not remarkable even after sitagliptin administration, which enhances GLP-1 secretion. Although GLP-1 is a powerful suppressor of glucagon secretion, the decrease in glucose levels should result in increased glucagon secretion, and the balance of these phenomena may lead to different degrees of changes in glucagon secretion. As discussed above, miglitol has been reported to enhance GLP-1 release. However, this was observed only in the patient in case 3 and the control subject, but not in the patients in cases 1 and 2. After sitagliptin was coadministered with miglitol, all the subjects showed incremental increases in GLP-1 levels, as expected, with different magnitudes. A recent report indicated that once-daily administration of miglitol at breakfast increased the 

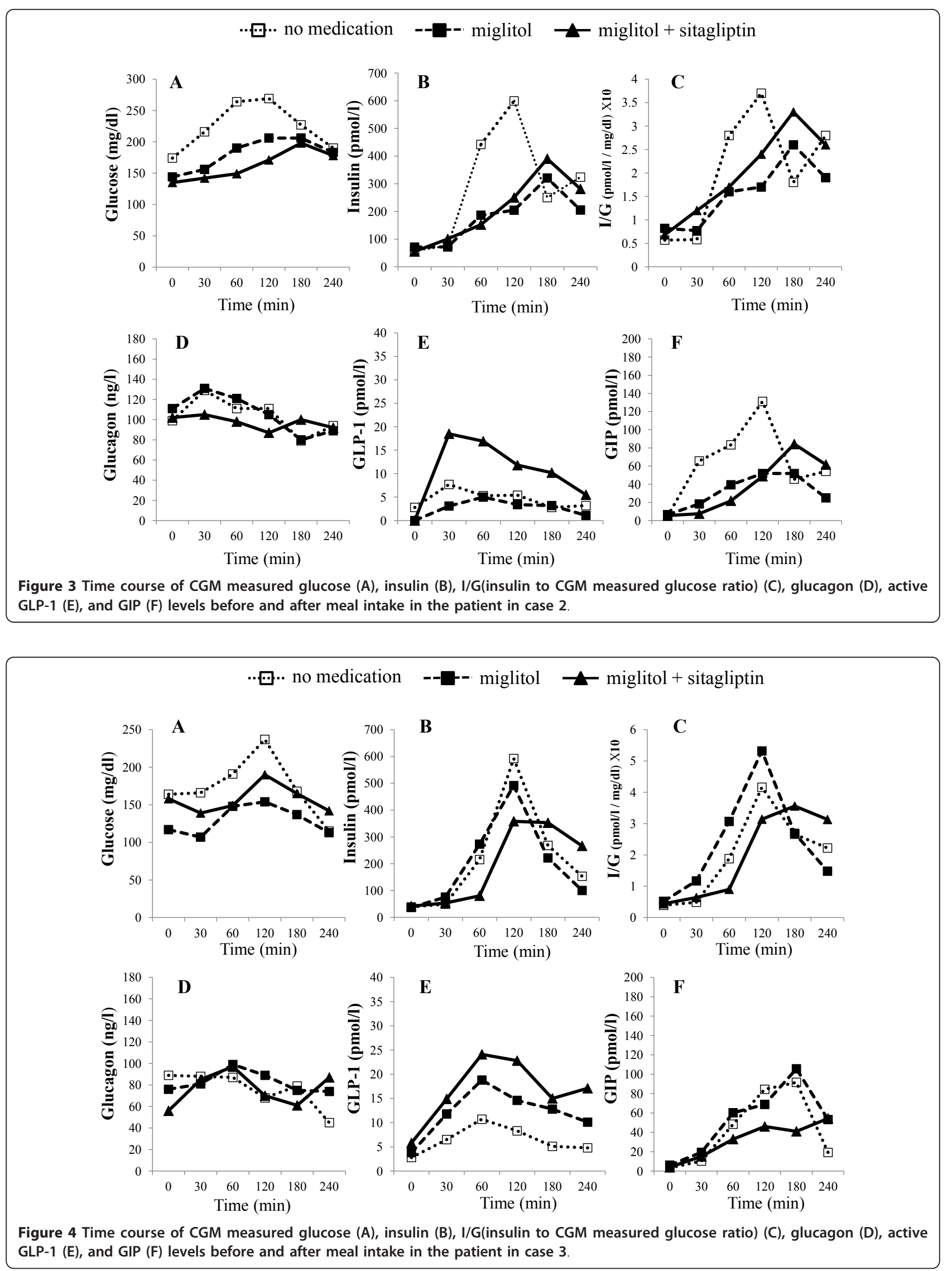


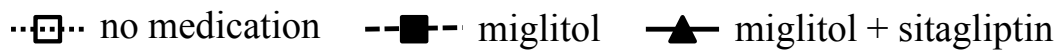
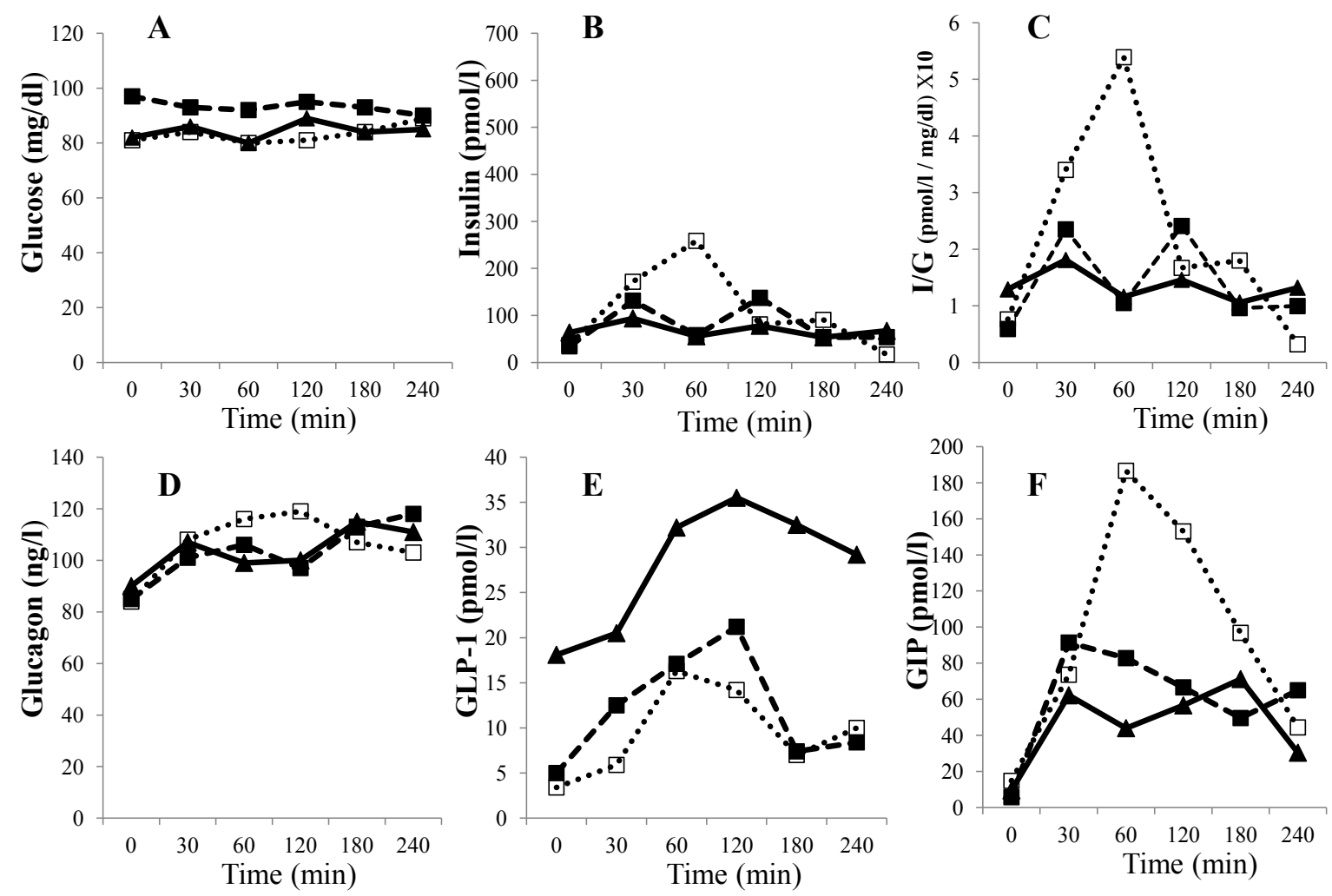

Figure 5 Time course of CGM measured glucose (A), insulin (B), I/G(insulin to CGM measured glucose ratio) (C), glucagon (D), active GLP-1 (E), and GIP (F) levels before and after meal intake in the patient in the control subject.

Table 3 Area under the curve (AUC) values during the 4-h meal test

\begin{tabular}{|c|c|c|c|c|}
\hline & Case 1 & Case 2 & Case 3 & Control \\
\hline \multicolumn{5}{|c|}{ Glucose (CGM) AUC $\left(10^{3} \mathrm{xmg} / \mathrm{dl} \cdot 4 \mathrm{~h}\right)$} \\
\hline no medication & 36.4 & 55.8 & 45.4 & 18.8 \\
\hline miglitol & 34.6 & 53.6 & 34.9 & 22.6 \\
\hline miglitol + sitagliptin & 30.2 & 40.1 & 39.0 & 20.3 \\
\hline \multicolumn{5}{|c|}{ Insulin AUC $\left(10^{3} \times \mathrm{pmol} / \mathrm{l} \cdot 4 \mathrm{~h}\right)$} \\
\hline no medication & 35.7 & 83.8 & 68.0 & 28.1 \\
\hline miglitol & 23.1 & 49.3 & 60.9 & 20.1 \\
\hline miglitol + sitagliptin & 36.7 & 57.6 & 56.5 & 16.2 \\
\hline \multicolumn{5}{|c|}{ Glucagon AUC $\left(10^{3} \times \mathrm{ng} / \mathrm{l} \cdot 4 \mathrm{~h}\right)$} \\
\hline no medication & 30.5 & 24.6 & 18.1 & 26.4 \\
\hline miglitol & 33.4 & 24.8 & 20.1 & 25.2 \\
\hline miglitol + sitagliptin & 34.1 & 23.1 & 18.2 & 25.2 \\
\hline \multicolumn{5}{|c|}{ GLP-1 (active) $\left(10^{3} \times \mathrm{pmol} / \mathrm{l} \cdot 4 \mathrm{~h}\right)$} \\
\hline no medication & 0.3 & 1.1 & 1.7 & 2.5 \\
\hline miglitol & 0.5 & 0.7 & 3.2 & 3.2 \\
\hline miglitol+sitagliptin & 5.0 & 2.8 & 4.4 & 7.3 \\
\hline \multicolumn{5}{|c|}{ GIP (total) $\left(10^{3} \times \mathrm{pmol} / \mathrm{L} \cdot 4 \mathrm{~h}\right)$} \\
\hline no medication & 15.1 & 18.0 & 13.7 & 27.1 \\
\hline miglitol & 8.3 & 9.4 & 15.4 & 15.5 \\
\hline miglitol + sitagliptin & 7.6 & 11.1 & 8.9 & 12.6 \\
\hline
\end{tabular}


AUC of active plasma GLP-1 levels even after lunch in sitagliptin-treated patients with type 2 diabetes [33]. Several studies have shown that patients with type 2 diabetes generally exhibit attenuated GLP-1 secretion [34-37], although others have reported normal GLP-1 secretion in these patients $[38,39]$. In our patients, GLP1 secretion was preserved and enhanced by administration of the DPP-4 inhibitor, but whether the levels of GLP-1 secretion were sufficient could not be determined. Future studies with larger numbers of patients will be required to investigate the clinical characteristics of patients who show a better GLP-1 response to sitagliptin (sitagliptin responders) and who are more likely to benefit from the treatments with the agents administered in this study. When miglitol is administered, the total GIP level is considered to decrease via an inhibition of glucose absorption in the upper intestine [15]; this tendency was also confirmed after 12-week administration of miglitol [18]. Our results, with the exception of 1 patient, are consistent with this theory. Among the subjects in this study, 1 patient and the control subject showed a remarkable decrease in GIP levels after the addition of sitagliptin, compared to miglitol administration alone, while the other subjects did not exhibit any change in GIP levels. Sitagliptin is reported to decrease the total GIP level [28], but this may not be applicable to all patients with type 2 diabetes. However, we can conclude that compared to no medication, all the subjects showed suppressed GIP levels when miglitol and sitagliptin were coadministered.

In conclusion, using CGMS, we revealed that a combination of the $\alpha$-GI, miglitol, and the DPP-4 inhibitor sitagliptin was effective in reducing glucose fluctuation and stabilizing postprandial blood glucose levels. A limitation of this study is the small number of subjects examined. For this reason, we cannot apply our results to the general population of type 2 diabetes patients. Our results do show completely different patterns of insulin, glucagon, GLP-1, and GIP responses to the study medications, suggesting that hormonal responses to the $\alpha$-GI and DPP-4 inhibitors differ among individuals, and that these responses may be complicated by multifactorial effects. Differences in hormonal responses to the drugs may partly be explained by differences in the duration of diabetes and pretreatment medication of our subjects. Further studies are needed to determine which other drugs would act in concert with DPP-4 inhibitors to effectively control postprandial hyperglycemia. Results from these additional studies would be of great interest in clinical practice.

\section{Acknowledgements}

This work was supported by a grant from the Joint Research Association for Japanese Diabetes.

\section{Authors' contributions}

MK made substantial contributions to the conception, design, acquisition of data, and drafting of this manuscript. MN assisted in critically revising the manuscript for important intellectual content. All authors read and approved the final manuscript.

\section{Competing interests}

The authors declare that they have no competing interests.

Received: 20 October 2011 Accepted: 22 December 2011 Published: 22 December 2011

\section{References}

1. Grundy SM, Cleeman Jl, Merz CN, Brewer HB Jr, Clark LT, Hunninghake DB, Pasternak RC, Smith SC Jr, Stone NJ: Coordinating Committee of the National Cholesterol Education Program. Implications of recent clinical trials for the National Cholesterol Education Program Adult Treatment Panel III guidelines. J Am Coll Cardiol 2004, 4:720-732.

2. Rosamond W, Flegal K, Friday G, Furie K, Go A, Greenlund K, Haase N, Ho M, Howard V, Kissela B, Kittner S, Lloyd-Jones D, McDermott M, Meigs J, Moy C, Nichol G, O'Donnell CJ, Roger V, Rumsfeld J, Sorlie P, Steinberger J, Thom T, Wasserthiel-Smoller S, Hong Y: American Heart Association Statistics Committee and Stroke Statistics Subcommittee: Heart disease and stroke statistics-2007 update: a report from the American Heart Association Statistics Committee and Stroke Statistics Subcommittee. Circulation 2007, 115:e69-e171.

3. Gong Su, Mi Shuhua, Tao Hong, Li Zhao, Yang Hongxia, Zheng Hong, Zhou Yun, Ma Changsheng: Association of glycemic variability and the presence and severity of coronary artery disease in patients with type 2 diabetes. Cardiovascular Diabetology 2011, 10:19.

4. Ceriello A, Esposito K, Piconi L, Ihnat MA, Thorpe JE, Testa R, Boemi M, Giugliano D: Oscillating glucose is more deleterious to endothelial function and oxidative stress than mean glucose in normal and type 2 diabetic patients. Diabetes 2008, 57:1349-1354.

5. Monnier L, Mas E, Ginet C, Michel F, Villon L, Cristol JP, Colette C: Activation of oxidative stress by acute glucose fluctuations compared with sustained chronic hyperglycemia in patients with type 2 diabetes. JAMA 2006, 295:1681-1687.

6. Hu Y, Liu W, Huang R, Zhang X: Postchallenge plasma glucose excursions, carotid intima-media thickness, and risk factors for atherosclerosis in Chinese population with type 2 diabetes. Atherosclerosis 2010, 210:302-306.

7. Temelkova-Kurktschiev TS, Koehler C, Henkel E, Leonhardt W, Fuecker K, Hanefeld M: Postchallenge plasma glucose and glycemic spikes are more strongly associated with atherosclerosis than fasting glucose or $\mathrm{HbA1c}$ level. Diabetes Care 2000, 23:1830-1834.

8. Risso A, Mercuri F, Quagliaro L, Damante G, Ceriello A: Intermittent high glucose enhances apoptosis in human umbilical vein endothelial cells in culture. Am J Physiol Endocrinol Metab 2001, 281:E924-E930.

9. Scheen AJ: Is there a role for alpha-glucosidase inhibitors in the prevention of type 2 diabetes mellitus? Drug 2003, 63:933-951.

10. Chiasson JL, Losse RG, Gomis R, Hanefeld M, Karasik A, Laakso M: STOPNIDDM Trial Research Group: Acarbose for prevention of type 2 diabetes mellitus: the STOP-NIDDM randomized trial. Lancet 359:2072-2077.

11. Ansar S, Koska J, Reaven PD: Postprandial hyperlipidemia, endothelial dysfunction and cardiovascular risk: focus on incretins. Cardiovasc Diabetol 2011, 10:61.

12. Drucker DJ: The role of gut hormones in glucose homeostasis. J Clin Invest 2007, 117:24-32.

13. Meier JJ, Nauck MA: Incretins and the development of type 2 diabetes. Curr Diab Rep 2006, 194-201.

14. Herman GA, Bergman A, Stevens C, Kotey P, Yi B, Zhao P, Dietrich B, Golor G, Schrodter A, Eymeulen B, Lasseter KC, Kipnes MS, Snyder K, Hilliard D, Tanen M, Cilissen C, De Smet M, de Lepeleire I, Van Dyck K, Wang AQ, Zeng W, Davies MJ, Tanaka W, Holst JJ, Deacon CF, Gottesdiener KM, Wagner JA: Effect of single oral doses of sitagliptin, a dipeptidyl peptidase-4 inhibitor, on incretin and plasma glucose levels after an oral glucose tolerance test in patients with type 2 diabetes. $J$ Clin Endocrinol Metab 2006, 91:4612-4619.

15. Narita T, Katsuura Y, Sato T, Hosoba M, Fujita H, Morii T, Yamada Y: Miglitol induces prolonged and enhanced glucagon-like peptide -1 and reduced 
gastric inhibitory polypeptide responses after ingestion of a mixed meal in Japanese Type 2 diabetic patients. Diabet Med 2009, 26:187-188.

16. Arakawa M, Ebato C, Mita T, Fujitani Y, Shimizu T, Watada H, Kawamori R, Hirose T: Miglitol suppresses the postprandial increases in interleukin 6 and enhances active glucagon-like peptide 1 secretion in viscerally obese subjects. Metabolism 2008, 57:1299-1306.

17. Lee A, Patrick P, Wishart J, Horowitz M, Morley JE: The effects of miglitol on glucagon-like peptide-1 secretion and appetite sensations in obese type 2 diabetics. Diabetes, Obes Metab 2002, 4:329-335.

18. Narita T, Yokoyama H, Yamashita R, Sato T, Hosoba M, Morii T, Fujita H, Tsukiyama K, Yamada Y: Comparison of the effects of 12-week administration of miglitol and voglibose on the responses of plasma incretins after a mixed meal in Japanese type 2 diabetic patients. Diabetes Obes Metab 2011.

19. Yamazaki K, Inoue T, Yasuda N, Sato Y, Nagakura T, Takenaka O, Clark R, Saeki T, Tanaka I: Comparison of efficacies of a dipeptidyl peptidase IV inhibitor and alpha-glucosidase inhibitors in oral carbohydrate and meal tolerance tests and the effects of their combination in mice. J Pharmacol Sci 2007, 104:29-38.

20. Moritoh Y, Takeuchi K, Hazama M: Combination treatment with alogliptin and voglibose increases active GLP-1 circulation, prevents the development of diabetes and preserves pancreatic beta-cells in prediabetic $d b / d b$ mice. Diabetes, Obes Metab 2010, 12:224-233.

21. Gross TM, Bode BW, Einhorn D, Kayne DM, Reed JH, White NH, Mastrototaro JJ: Performance evaluation of the MiniMed Continuous Glucose Monitoring System during patient home use. Diabetes Technol Ther 2000, 2:49-56.

22. Kaufman FR, Gibson LC, Halvorson M, Carpenter S, Fisher LK, Pitukcheewanont P: A pilot study of glucose measurements using the glucose sensor. Diabetes Care 2002, 25:1185-1191.

23. Sachedina N, Pickup JC: Performance assessment of the MedtronicMiniMed Continuous Glucose Monitoring System and its use for measurement of glycaemic control in type 1 diabetic subjects. Diabet Med 2003, 20:1012-1015.

24. The committee of Japan Diabetes Society on the diagnostic criteria of diabetes mellitus: Report of the Committee on the classification and diagnostic criteria diabetes mellitus. J Jpn Diabetes Soc 2010, 53:450-467.

25. Dungan KM, Buse JB, Largay J, Kelly MM, Button EA, Kato S, Wittlin S: 1,5Anhydroglucitol and postprandial hyperglycemia as measured by continuous glucose monitoring system in moderately controlled patients with diabetes. Diabetes care 2006, 29:1214-1219.

26. Yamanouchi T, Minoda S, Yabuuchi M, Akanuma Y, Akanuma $\mathrm{H}_{\text {, }}$ Miyashita H, Akaoka I: Plasma 1,5-Anhydro-D-Glucitol as new clinical marker of glycemic control in NIDDM patients. Diabetes 1989, 38:723-729.

27. Aoki K, Masuda K, Miyazaki T, Togashi Y, Terauchi Y: Effects of miglitol, sitagliptin or their combination on plasma glucose, insulin and incretin levels in non-diabetic men. Endocrine J 2010, 57:667-672.

28. Bock G, Man CD, Micheletto F, Basu R, Laugen J, Deacon CF, Holst JJ, Toffolo G, Cobelli C, Rizza RA, Vella A: The effect of DPP-4 inhibition with sitagliptin on incretin secretion and on fasting and postprandial glucose turnover in subjects with impaired fasting glucose. Clin Endocrinol (Oxf) 2010, 73:189-196.

29. Maruyama H, Hisatomi A, Orci L, Grodsky GM, Unger RH: Insulin within islets is a physiologic glucagon release inhibitor. J Clin Invest 1984, 74:2296-2299.

30. Holst JJ, Christensen M, Lund A, de Heer J, Svendsen B, Kielgast U, Knop FK Regulation of glucagon secretion by incretins. Diabetes, Obes Metab 2011, 13:89-94.

31. de Heer J, Rasmussen C, Coy DH, Holst JJ: Glucagon-like peptide-1, but not glucose-dependent insulinotropic peptide, inhibits glucagon secretion via somatostatin (receptor subtype 2) in the perfused rat pancreas. Diabetologia 2008, 51:2263-2270.

32. Cejvan $\mathrm{K}$, Coy DH, Efendic S: Intra-islet somatostatin regulates glucagon release via type 2 somatostatin receptors in rats. Diabetes 2003, 52:1176-1181.

33. Aoki K, Kamiyama H, Yoshimura K, Shibuya M, Masuda K, Terauchi Y: Miglitol administered before breakfast increased plasma active glucagon-like peptide-1 (GLP-1) levels after lunch in patients with type 2 diabetes treated with sitagliptin. Acta Diabetol 2011.
34. Vilsbøll T, Krarup T, Deacon CF, Madsbad S, Holst JJ: Reduced postprandial concentrations of intact biologically active glucagon-like peptide I in type 2 diabetic patients. Diabetes 2001, 50:609-613.

35. Nauck M, Stockmann F, Ebert $R$, Creutzfeldt W: Reduced incretin effect in type 2(non-insulin-dependent) diabetes. Diabetologia 1986, 29:46-52.

36. Toft-Nielsen MB, Madsbad S, Holst JJ: Determinants of the effectiveness of glucagon-like peptide-1 in type 2 diabetes. J Clin Endocrinol Metab 2001, 86:3853-3860.

37. Rask E, Olsson T, Söderberg $\mathrm{S}$, Johnson O, Seckl J, Holst JJ, Ahrén B: Impaired incretin response after a mixed meal is associated with insulin resistance in nondiabetic men. Diabetes Care 2001, 24:1640-1645.

38. Vollmer K, Holst JJ, Baller B, Ellrichmann M, Nauck MA, Schmidt WE, Meier JJ: Predictors of incretin concentrations in subjects with normal, impaired and diabetic glucose tolerance. Diabetes 2008, 57:678-687.

39. Ryskjaer J, Deacon CF, Carr RD, Krarup T, Madsbad S, Holst J, Vilsbøll T: Plasma dipeptidyl peptidase-IV activity in patients with type 2 diabetes mellitus correlates positively with $\mathrm{HbA}_{1 c}$ levels, but is not acutely affected by food intake. Eur J Endocrinol 2006, 155:485-493.

doi:10.1186/1475-2840-10-115

Cite this article as: Kishimoto and Noda: A pilot study of the efficacy of miglitol and sitagliptin for type 2diabetes with a continuous glucose monitoring system and incretin-related markers. Cardiovascular

Diabetology 2011 10:115.

\section{Submit your next manuscript to BioMed Central and take full advantage of:}

- Convenient online submission

- Thorough peer review

- No space constraints or color figure charges

- Immediate publication on acceptance

- Inclusion in PubMed, CAS, Scopus and Google Scholar

- Research which is freely available for redistribution

Submit your manuscript at www.biomedcentral.com/submit
Ciomed Central 